\title{
BIM ORIENTATION: GRADES OF GENERATION AND INFORMATION FOR DIFFERENT TYPE OF ANALYSIS AND MANAGEMENT PROCESS
}

\author{
F. Banfi ${ }^{\text {a }}$
}

\author{
${ }^{a}$ ABC Department, Politecnico di Milano, Piazza Leonardo da Vinci 32, Milan, Italy \\ fabrizio.banfi@polimi.it \\ http://www.gicarus.polimi.it
}

\author{
Commission VI, WG VI/4
}

KEYWORDS: Scan to BIM, Building Information Modeling (BIM), Modelling\&Management Information System (MMIS), Grade of Generation (GoG), Grade of Information (GoI), Grade of Accuracy (GoA)

\begin{abstract}
:
Architecture, Engineering and Construction (AEC) industry is facing a great process re-engineering of the management procedures for new constructions, and recent studies show a significant increase of the benefits obtained through the use of Building Information Modelling (BIM) methodologies. This innovative approach needs new developments for information and communication technologies (ICT) in order to improve cooperation and interoperability among different actors and scientific disciplines. Accordingly, BIM could be described as a new tool capable of collect/analyse a great quantity of information (Big data) and improve the management of building during its life of cycle (LC). The main aim of this research is, in addition to a reduction in production times, reduce physical and financial resources (economic impact), to demonstrate how technology development can support a complex generative process with new digital tools (modelling impact). This paper reviews recent BIMs of different historical Italian buildings such as Basilica of Collemaggio in L'Aquila, Masegra Castle in Sondrio, Basilica of Saint Ambrose in Milan and Visconti Bridge in Lecco and carries out a methodological analysis to optimize output information and results combining different data and modelling techniques into a single hub (cloud service) through the use of new Grade of Generation (GoG) and Information (GoI) (management impact). Finally, this study shows the need to orient GoG and GoI for a different type of analysis, which requires a high Grade of Accuracy (GoA) and an Automatic Verification System (AVS ) at the same time.
\end{abstract}

\section{INTRODUCTION}

\subsection{General context}

The growing demand of BIM based method is drastically changing the management of existing buildings and connecting sub-fields such as restoration, preservation, prevention, rehabilitation and maintenance in the most developed countries. This new source is also causing an exponential growth of applications, modelling tools, exchange format lists and a consequent increase of new eminent professions such as BIM Manager, Modeller, 3D detector, API (Application programming interface) developer and IT.

The experience acquired over the last years by typical architects and engineers should be redirected to support these new digital developments. They could lead to a revival of the entire construction sector and improve the management of building in digital environments.

The following study gives a synthetic overview of the main experience gained directly on the field and shows how an appropriate generation of as-built BIM could become a useful tool for managing information during the lifecycle of the building. Improvement of the intangible value of the built heritage (Information Management) should be supported by an appropriate construction of the digital model (BIM generation). The integration of these two factors is fundamental in order to obtain a fruitful source for different types of analysis (BIM Orientation). BIM is a new management tool, and as such, it needs to be developed in various ways, promoting its flexibility and interoperability over time.

This study summarizes the generative processes of recent case studies through the use of new Grades of Generation (GoG) for Italian-built heritage, demonstrating how modelling could have been a decisive factor for representing, linking and managing appropriately different Grades of Information (GoI).

These new parameters have been used to define the HBIMs developed from the qualitative (big data) and quantitative (accuracy) point of view, allowing users to relate directly to different types of analysis: design, finite element analysis, cost management, virtual reality, energy analysis, etc..

The innovative use of 3D Data techniques (Laser Scanning and Photogrammetry) and the integration between BIM Application and NURBS modelling has shown how it is possible to implement the generative process of complex structures, reducing time and cost and improve the dissemination of various type of information and detailed BIM-based analysis at the same time. 


\subsection{Problem Statement}

BIM research is producing interesting studies on existing buildings with the primary goal of promoting restoration projects and built heritage through various types of analysis based on the advanced use of parametric models (Volk 2014). Thanks to the latest technological developments, the generative process of the parametric model is based on the use of advanced 3D technology such as laser scanning and photogrammetric techniques (terrestrial and UAV). Thanks to their wellestablished benefits, the attention has shifted to the definition of national parameters, guidelines and specifications that can hierarchize the quality of the product model and can provide accurate information to the different users of the actual conditions of the product at the same time.

In various countries, the levels of detail (LoD) and information levels (LoIs) have been defined with the aim of transmitting the conditions (morphological and typological) of the models produced (American Institute of Architects 2013; BIMForum 2013; AEC CAN BIM 2012). In recent years only, few studies have established guidelines for a proper hierarchy of historical and existing models based on 3D surveys (Fai 2014, Quintero 2003). Advanced Modeling Techniques (AMT) require a high level of knowledge and could represent the proper tool for the generation of complex 'Scan to BIM' element. Unfortunately, AMT is not included in BIM application. One of the main reason is the difficulty given by parametric applications to create complex and irregular shapes, while at the same time keeping high levels of accuracy (GoA) between point clouds and $3 \mathrm{D}$ objects. To better understand the difficulty of reengineering AEC sector and its complex regulatory networks, it is necessary to consider the various modeling applications available on the market such as, Graphisoft ArchiCAD, Mc Neel Rhinoceros, Bentley Microstation, Autodesk Revit, just to name a few. Each application allows the generation of a digital model of the same building. Compared to each other, they present a significant number of differences such as geometric primitives, constructive logic, modeling language, constructive logic, exchange formats (.dxf, .dwg, .skp, .Pln, .3dm, .dgn, .rvt etc) resulting in the exponential growth of BIM-based analysis software, not always convincingly. The information exchange set up under this process, consisted mainly of geometric entities and related information which can produce different results and analyses from model to model. In even more confusing cases different results for same models of the same building.

The rigidity of the database and modeling tools in BIM application required the introduction of a new system that could define not the model's LoD, but rather the modeling itself. The modeling has been the main factor that have improved the quality of BIMS, information flow and not. In support of this study, international statistical surveys show that even in the UK, where BIM is mandatory, the BIM maturity level 3 has not been widely spread (NBS 2016). This lack of development has been caused by a number of factors, including the complexity of traditional reengineering methods in new digital experiences such as BIM, VR, etc., high conversion costs, learning difficulties of new digital techniques at early stages of use, the adaptation to acerbic regulations and inability to support technological upgrades etc. The absence of AMT able to interpolate the points that make up $3 \mathrm{~d}$ scans and obtain 3D objects in BIM applications has been the major modeling constraint.In pure modeling software, it is possible to generate and define NURBS algorithms capable of generating complex three-dimensional entities directly from point clouds without having to invest in long modeling phases (Piegl 1997).

\subsection{Research Objectives}

The development of AMT have provided great opportunities to enhance GoG in BIM applications. The Basilica of Colleamaggio, Masegra Castle, Basilica of Sant'Ambrogio and the Visconti Bridge have been real case studies where BIM has been the protagonist during the phases of design, architectural analysis, structural analysis, monitoring, etc., favouring the development of different GoI during the life cycle of the buildings.

The definition of these new degrees has been the primary objective in order to give significant support to the process of building upgrades, focusing on reading and the proper use of models.

The real challenge for this study was to improve the HBIM's ability to adapt to the holistic needs of experts involved in different phases of restoration projects. This need has required the definition and the parametrization of novels GoGs in BIM application, able to create complex vault system, arches, damaged walls and other complex structural elements for each case studies.

Therefore the research objectives are:

- To emphasise the need to integrate NURBS modeling into BIM applications through innovative research, showing how the NURBS complex object creation process (Scan to BIM) can directly interact with one of the most widely used applications (BIM Orientation),

- To classify and define the GoGs used to generate asbuilt (As-built BIMs)

- To classify and determine the GoIs applied to each case study case,

- To classify and define a validation method for 'Scan to BIM' based on GoAs for each case study

- To show the need to orient GoG and GoI for different type of analysis, requiring a GoA and an Automatic Verification System (AVS )

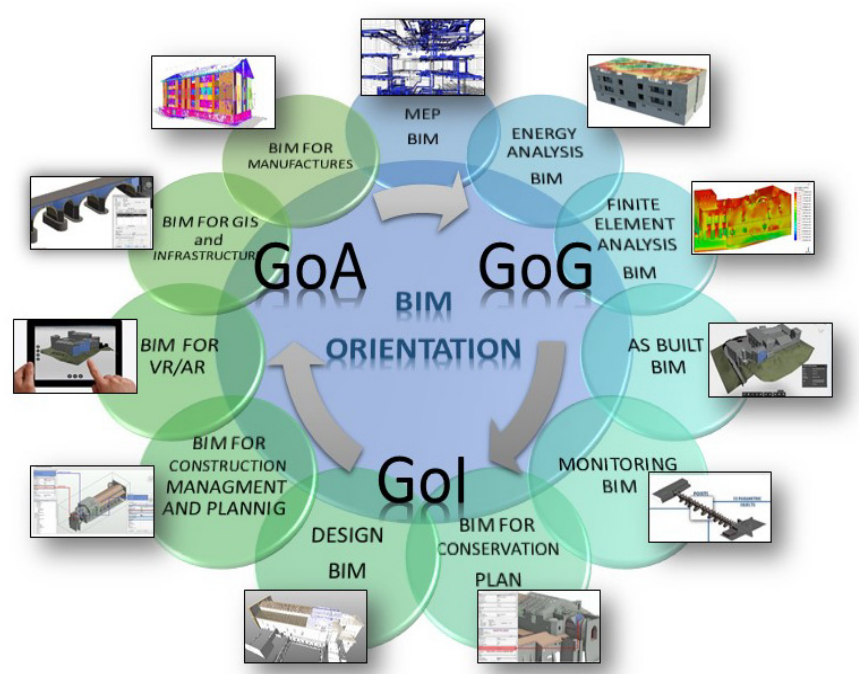

Fig. 1.Future of BIM Orientation: a BIM's holistic view can be oriented for different disciplines and analysis, stimulating a better dissemination of various results. Each analysis has needed different GoG, GoA and GoI. 


\section{MODELING \& MANAGEMENT INFORMATION SYSTEM (MMIS)}

\subsection{MMIS of four Italian case studies: an invaluable research field}

The BIM acronym is composed of three factors that are closely related to one another. One of the main features of this new digital management system is the bidirectionality between $M$ (Modeling) and I (Information), favouring advanced B (Building) analysis. Linking the information to the parametric models was the main added value of the models in order to define their utility (Banfi 2016)

The generation of HBIM has involved long architectural and structural analysis of the building. These tests have been characterised by an in-depth study of a huge amount of data (big data) which has determined the historical treasures of the buildings. The major challenge for existing and historic buildings models has been the correct association of information with the digital model.

Based on the assumption that the information defines every single 3D object, it has been clear that different studies based on BIM logic have required appropriate GoGs in order to establish the new paradigm of the complexity of historic buildings.

The BIM, born principally for the management of new buildings, is becoming a real benefit also for the heritage of the built. The dissemination of this new tool, however, is currently facing a number of significant challenges, mainly based on the lack of modeling techniques in BIM applications.

HBIM of the Basilica of Collemaggio in L'Aquila was among the first examples in the Italian territory to incorporate advanced 3D survey techniques (Barazzetti 2014), pure and parametric modeling, increasing the quality and management of the restoration process after the earthquake of 2009. Architectural elements and damaged structures have required new GoGs and GoIs, by the design requirements and structural calculations of particular areas of the building (Crespi 2015).

HBIM of Masegra Castel in Sondrio was the first digital model for large historical buildings in Italy to integrate a large number of historical, structural and architectural information with complex 3D objects able to represent 3D data scans correctly (Barazzetti 2015). Each type of vault, arch, pillar, and the irregular wall has been generated thanks to NURBS algorithms able to interpolate the points that make up the 3D scans. This modeling techniques have required a new definition of $\mathrm{GoG}$ and GoI not present in BIM applications, useful in identifying complex elements for different types of analysis.

HBIM of Visconti Bridge has given the opportunity to guide the generation of a mediaeval infrastructure at various needs. The geometric and structural peculiarities of the bridge have needed several 3D survey phases, on-site analysis, and structural monitoring over time. The conservation and maintenance plan has provided for the analysis of different GoI, both morphological and typological. This particular need required the development of a digital model capable of supporting cooperation between different disciplines using a central workspace (Banfi 2017).

The development of the AMT, in recent years, has identified a lack of the various national guidelines for the definition of LoDs. Innovative and world-wide-established studies have structured their complex BIM process on an internal and improved definition of LoD. This aspect has made it possible to emphasise how the reference classes can be defined in an entirely independent way, trying to achieve specific project objectives by aligning producer and customer through specific qualitative and quantitative parameters.

BIM is not yet mandatory in most parts of Europe. The high requirements, complex guidelines, rigid protocols and standards are the main reasons for the difficult situation of the European AEC industry. This research shows how generative flexibility should become the first and only capability to allow the evolution, both qualitatively and quantitatively, of complex digital models.

This factor implies the need to create models with GoG, GoI, and GoA that change over time and can integrate into one single hub. Modeling and Management Information System (MMIS) has been the key to the proper management of HBIMs, allowing geometric model definition, clustering of various degrees of information, and finally classifying each single 3D object based on a control system that determines the accuracy of the model.

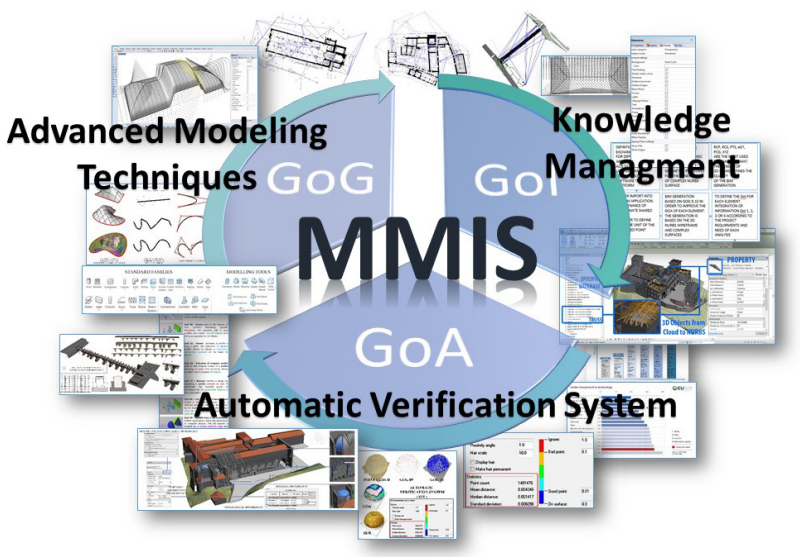

Fig. 2. BIM viewed as a Modelling\&Management Information System (MMIS) based on the integration of Grades of Generation (GoG), Grades of Information (GoI) and Grade of Accuracy (GoA). MMIs defined ADT, KM and AVS for each case study

\subsection{Advanced Modeling Techniques (AMT) and NURBS geometric primitives for 'Scan to BIM'}

The latest generations are attending BIM's large-scale application for new buildings. Thanks to its high benefits, these new building management tools have become part of the national regulations in the UK. In recent years, innovative studies and projects are developing this technology for existing buildings, trying to benefit not only in economic terms but management, restoration and maintenance terms as well.

This article summarises how it has been possible to improve the generative process of historic Italian case studies, favouring asset management through the original orientation of digital models.

The first constraint has been imposed by the lack of complex 3D objects such as vaults, irregular walls, arches, pillars and decorations in BIM databases. The second constraint has been the lack of AMT in BIM applications able to generate architectural elements in a short time. The absence of these factors in parametric software has led to the study of the most common generative techniques, with the aim of reducing the time and cost of long modeling phases.

The application market offers a wide range of products, based on modeling logic and different exchange formats. These new tools can be divided into categories: pure modeling applications 
(NURBS modeling) and parametric applications (BIM software). Non-Uniform Basis Splines modeling is known for its extreme flexibility in generating complex shapes.

On the other hand, BIM applications are known for the parameterization concept that allows bi-directional relationships between information, data, and 3D objects. Each 3D object included in BIM libraries represents architectural and structural elements to which a large number of information can be associated. One of the greatest benefits is the ability to change and update dimensional values, materials, etc. without having to remodel. The update, from the morphological and typological point of view, is automatic and bi-directional.

The definition of NURBS algorithms and the use of geometric primitives has allowed us to identify a method capable of guiding NURBS mathematical functions and their complex forms from pure modeling to parametric environments. BIM modeling tools like blend, swept blend (GoG 07,08) can not interpolate and extract complex surfaces directly from point clouds. The following study has introduced two GoGs ( 9 and $10)$ in the generative process. The automatic interpolation of NURBS geometric primitives has determined the creation of multiple elements from point clouds with high grades of accuracy.In the last paragraph, it is described the real need to have the highest GoA for 'Scan to BIM' in order to reach an Automatic Verification System (AVS) able to calculate a deviation value between point clouds and $3 \mathrm{D}$ object.

This novel modeling method has allowed to create complex buildings and structures, exponentially reducing production times. At the same time, the integration of NURBS models in the parametric environment has enabled the orientation of the models for different types of information, analysis and BIMbased simulation. Figure 3 describes the generating process for 'Scan to BIM' models. This process is characterised by the automatic extraction of NURBS primitive for BIM applications.

\begin{tabular}{|c|c|c|}
\hline \multicolumn{3}{|c|}{ MODELING MANAGMENT INFORMATION SYSTEM (MMIS) } \\
\hline $\begin{array}{l}\text { 3D DATA CAPTURE OF } 1 \\
\text { THE BUILDINGS BY } \\
\text { PHOTOGRAMMETRIC } \\
\text { TECHNIQUEAS, } \\
\text { LASER SCANNIG ANT } \\
\text { THE INTEGRATION WITH } \\
\text { GEODETIC NETWORK BY } \\
\text { TOTAL STATION }\end{array}$ & $\begin{array}{l}\text { EXPORT OF POINT } \\
\text { CLOUDS FROM LASER } \\
\text { SCANNER SOFTWARE } \\
\text { AND PROFESSIONAL } \\
\text { TOOL FOR } \\
\text { PHOTOGRAMMETRY } \\
\text { PIPELINE INTO RECAP, } \\
\text { RHINOCEROS ETC. }\end{array}$ & $\begin{array}{l}\text { DEFINTION OF } \\
\text { EXCHANGE FORMATS } \\
\text { FOR DIFFERENT } \\
\text { ADVANCED MODELLING } \\
\text { APPLICATION SUCH AS } \\
\text { RHINOCEROS, } \\
\text { MICROSTATION, } \\
\text { SDSTUDIO MAX, ETC }\end{array}$ \\
\hline $\begin{array}{l}\text { DEFINTION OF } \\
\text { EXCHANGE SCHEMAS } \\
\text { FOR DIFFERENT BIM } \\
\text { APPLICATION. DWG AND } \\
\text { ACIS SAT ARE THE MOST } \\
\text { USED EXCHANGE } \\
\text { FORMAT FROM NURBS } \\
\text { SOFTWARE TO BIM } \\
\text { PLATFORM }\end{array}$ & $\begin{array}{l}\text { DEFINTION OF GOG } \\
\text { FOLLOWING THE } \\
\text { CONSTRUCTION LOGIC } \\
\text { OF THE BUILDINGS. } \\
\text { EXTRACTION OF } \\
\text { GEOMETRIC PRIMITIVES } \\
\text { FOR THE GENERATION } \\
\text { OF COMPLEX NURBS } \\
\text { SURFACE }\end{array}$ & $\begin{array}{l}\text { RCP, RCS, PTS, e57, } \\
\text { PCG, XYZ } \\
\text { ARE THE MOST USED } \\
\text { EXCHANGE FORMAT. } \\
\text { THE DENSITY OF } \\
\text { 3D SCANS DEFINES THE } \\
\text { QUALITY } \\
\text { OF THE BIM } \\
\text { GENERATION }\end{array}$ \\
\hline $\begin{array}{l}\text { PROPER IMPORT INTO } 7 \\
\text { THE BIM APPLICATION. } \\
\text { MAINTENANCE OF } \\
\text { COORDINATE SHARED } \\
\text { SYSTEM } \\
\text { IN ORDER TO DEFINE } \\
\text { THE SAME UNIT OF THE } \\
\text { COLLETED POINT } \\
\text { CLOUDS }\end{array}$ & $\begin{array}{l}\text { BIM GENERATION } \\
\text { BASED ON GOG } 9,10 \text { IN } \\
\text { ORDER TO IMPROVE THE } \\
\text { GOA OF EACH ELEMENT. } \\
\text { THE GENERATION IS } \\
\text { BASED ON THE 3D } \\
\text { NURBS WIREFRAME } \\
\text { AND COMPLEX } \\
\text { SURFACES }\end{array}$ & $\begin{array}{l}\text { TO DEFINE THE GOI } \\
\text { FOR EACH ELEMENT. } \\
\text { INTEGRATION OF } \\
\text { INFORMATION GOI 1, } \\
2,3 \text { OR } 4 \text { ACCORDING } \\
\text { TO THE PROJECT } \\
\text { REQUIRMENTS AND } \\
\text { GOALS OF EACH } \\
\text { ANALYSIS }\end{array}$ \\
\hline $\begin{array}{l}\text { FOR DIFFERENT TYPE OF } \\
\text { ANALYSIS BASED ON } \\
\text { VARIOUS TRADITION } \\
\text { TYPE OF LOD,LOI \& LOA }\end{array}$ & $\begin{array}{l}\text { MODELING } \\
\text { MANAGEMENT } \\
\text { INFORMATION SYSTEM } \\
\text { ALLOWED THE } \\
\text { DEFINITION OF } \\
\text { TRADITIONAL LEVEL OF } \\
\text { DETAIL FOR ANALYSIS }\end{array}$ & $\begin{array}{l}\text { CHECKING SYSTEM OF } 10 \\
\text { 3D OBJECTSTO DEFINES } \\
\text { THE GOA OF THE } \\
\text { MODEL. 'SCAN TO BIM'. } \\
\text { METHOD ALLOWS } \\
\text { (GOA) ACCURACY } 1-2 \\
\text { Mm FOR COMPLEX BIM }\end{array}$ \\
\hline
\end{tabular}

Fig. 3. The benefits of MMSI are not limited to morphological and geometric aspects, but to improve the management information of intangible values of the built heritage

\section{BIM ORIENTATION}

\subsection{The definition of Grade of Generation (GoG)}

The management of historic and existing buildings directly clashes with the difficulty of expanding the information system of the building in a digital environment. MMIS is structured on a free generative logic that can be implemented during the life cycle of the building. It does not require representational constraints, but rather geometric entities (3D Objects), which in turn contain information (descriptive data), and the accuracy $3 \mathrm{D}$ survey and parametric model (deviation value).

The first challenge, for better MMIS, has been figure out the right way to create complex architectural and structural elements (Scan to BIM). The BIM restoration project of the Basilica of Collemaggio has made possible to highlight a useful research line in order to improve geometric entities and to associate specific information such as the conservation plan, calculations, historical phases, costs, etc.

Modeling complex elements have been the basis for an appropriate generation of the historic parametric model. As already described in the previous paragraph, NURBS modeling has been detected of significant utility, thanks to the significant reducing in costs and times related to the creation of models. The flexibility of modeling has ensured a combination of information aligned with the needs of the various projects such as a restoration project, structural a finite element analysis, monitoring analysis, mixed (VR-AR) reality environments, etc. This new factor has led to the definition of qualitative and quantitative parameters of the four models carried out in the previous years.

The proposed GoGs directly have analysed internal modeling commands and have been able to progressively define a simple and intuitive reference scale.

In the following figure (Fig.4) it is possible to understand the requirements of this reference scale composed of ten GoG (from 1 to 10). The latter level requires advanced knowledge in order to manage NURBS Modeling and exchange formats. G09 and G10 have been based on NURBS algorithms (not present in BIM applications) and have allowed the definition of damaged, irregular and complex objects that distinguish the buildings taken into account. They do not represent the highest level of quality of the parametric model, but rather grades of generation useful for particular types of analysis (Structural Analysis, Finite Element Analysis, Conservation Plan, Decay Analysis, etc.). The capacity of an as-built parametric model is the ability to relate to project requirements freely, enabling bi-directional information flows. An entire model can be entirely characterised by a GoG 1 or the alternation of all GoGs (from 1 to 10). They can coexist in harmony in the same BIM, providing more stability at the $3 \mathrm{D}$ reconstruction. The real benefits of a system capable of attaching any information can be obtained if every single architectural and structural element is realised. This has allowed logging into BIM logic, to connect/create and orient any information and automatically compute each element, maintaining an Information Management System parametric type. AMT's integration has been a decisive contribution to represent complex forms of historic buildings characterised by irregular walls, complex vault systems, pillars and arches of various types.

These geometric peculiarities have been represented by going beyond the simple basic modeling offered by the parametric software. 
The image shows ten GoGs, from the simplest to the most complex. Each GoG is geometrically represented by its primitive geometric properties, the required modeling transformation and the final 3D object.

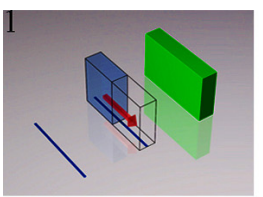

GoG 01 - Extrusion extends the shape of straight line along an orthogonal direction. It represents the first grade of generation for 3D parametric objects in BIM application.

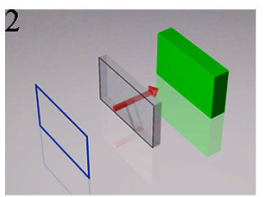

GoG 02 - Edit Profile extends the shape of a Gortit prof plane into 3D space. It's possible edit the profile and to have adirect updating of the $3 D$ objects shape. It represents the second grade of generation for 3D parametric objects in BIM application.

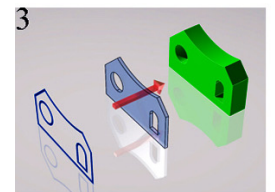

GoG 03 - Edit Profile with empty spaces extends the shape of multiple profile following an orthogonal direction. It's possible edit its profile andto create empty spaces. It represents the third grade of generation for 3D parametric objects in BIM application.

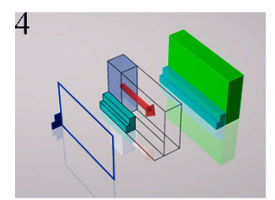

GoG 04 - Sweep extends the shapes of two profiles following specific directions. It's possible add a new profiles and to create sub3D objects with difference geometric primitives. It represents the fourth grade of generation for 3D parametric objects in BIM application.

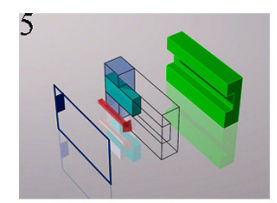

GoG 05 - Reveal extrudes a profile a long a path. The extrusion of second profile allows to obtain a volumetric subtraction (cutout) of the main 3D object. It represents the fifth grade of generation for 3D parametric objects in BIM application.

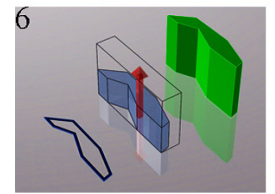

GoG 06 - Extrusion of irregular profile extends the irregular shape of a profile following an path. The extrusion allows to obtain more complexity for the volume. It represents the sixth grade of generation for 3D parametric objects in BIM application.

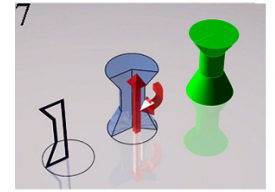

GoG 07 - Revolve creates a shape by sweeping a profile around an axis. It represents the seventh grade of generation for 3D parametric objects in BIM application.

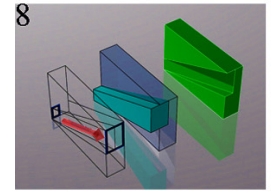

GoG 08 - Loft, Sweep and Sweept blend create a blend that sweeps along a defined path. The shape is determined by the profiles. Each GoG allow to use voids in order to remove part of the main 3D object. It represents the eighth grade of generation for 3D parametric objects in BIM application.

NEW GRADES OF GENERATION (GOG) FOR AS-BUILT BIM

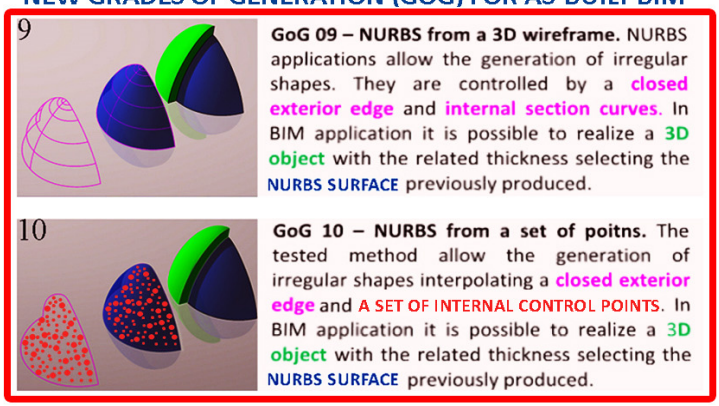

Fig. 4. Grades of Generation (GoG) for existing and HBIMs. The tested method has allowed the parametrization of complex 3D Object. BIM application needs GoG 9 and 10 in order to permit the automatic generation of complex $3 \mathrm{D}$ objects from point clouds.

\subsection{The definition of Grade of Information (GoI)}

The study conducted over the last five years on the complex generation of digital models based on accurate 3D surveys has developed a generative technique that can guide the information flow to different types of analysis.

These types of analysis could increase the accuracy of tests and simulations thanks to an appropriate model generation.

The next step has been to define the geometric model with a large amount of information from different teams of experts. This request has highlighted the need to figure out a method capable of using the BIM created for various needs (GoI 1,2,3). This claim has mainly shown that

- the complexity needs to be oriented to project requirements while simultaneously involving the use of multiple GoGs and GoIs for different types of analysis.

- the project goals have demanded to ensure qualitative and quantitative levels of the BIM for all teams involved into the process.

- Contractors and experts involved have highlighted that the main feature of the models must be the flexibility.

The concept of bidirectionality applied to the Visconti Bridge, and Masegra Castle has been based on several GoGs and appropriate GoIs. Every single 3D object created in the different case studies represents not only the irregular, computable and recognisable geometric shapes by various BIMbased analysis applications, but also a list of information that can accurately define the richness of the digital model over time.

This 'time factor' has determined two concepts:

- the need to maintain a high level of model flexibility without any generic and descriptive constraints

- ex-ante defining 'how' and 'how much knowledge' should be included in digital databases during building lifecycle is a real limitation for a digital system that can implement the knowledge level of the building without limit.

The bidirectional progression of the GoIs has provided a semiautomatic information definition (GoI 01) and an integration of more specific features such as material analyses, stratigraphy, physical and thermal characteristics (GoI 02).

The further step has been to create new internal/external databases to the BIM application that can bi-directionally link the 3D object and inserted data while ensuring automatic counts (GoI 03). Given this degree of definition, for each single model, it has been possible to reach an appropriate BIM orientation for different types of analysis, avoiding re-modeling, recreating and orienting models again. The latest GoI has no limits and constraints and can be implemented over time by using a shared hub where all interdisciplinary tasks can be coordinated.

The traditional definition of LoDs and LoI is not to be confused with the various GoG and GoIs. These grades represent macro sets / phases where different experts have to engage with different types of analysis, while LoDs describe specific requirements for sub BIM fields such as BIM Design, Construction Site BIM Monitoring, BIM for Conservation Plan, BEM (Energy Analysis). BIM for Facility Management, BIM for Infrastructure, BIM for cloud computing, etc 
The GoI 01 has allowed the definition of the following information for each architectural and structural element:

- Usage: Structural or Architectural

- Dimensions: Height, Width, Length, Area, Volume

- Identity Data: Type, Image, Keynote, Model, Manufacturer, Type comments, URL, Description, Assembly code, Type Mark, Fire Rating, Cost

- Phasing: Created: Existing or New Construction;

- Demolished - Existing or New Construction

- Function: Interior, Exterior, Foundation, Retaining, Soffit

- Material and finishes: Family, Type, Total thickness, Resistance (R), Layer and stratigraphic information

The GoI 02 has increased the level of information. It includes:

- Analytical Properties: Heat Transfer Coefficient (U), Thermal Resistance (R), Thermal Mass, Absorbance,

- Physic and Thermal Material Information : Name, Description, Keyword, Type, Subclass, Source, Source URL, Properties, transmit light, Behaviour Isotropic or Orthotropic, Thermal conductivity, Specific heat, Density, Emissivity, Permeability, Porosity, Reflectivity, Electrical resistivity, Density, Young's module, Poisson's ratio, linear modulus, Yield strength, tensile strength

- Appearance: Information name, description, keywords, wall paint, finish application, Tint

- Graphics: Shading, Colour, Transparency, Surface pattern, Colour alignment, Texture, Mapping

The GoI 03 represents a cloud-based holistic system where all the involved users can improve the knowledge of built heritage. BIM required an orientation for various disciplines. Each discipline has implemented the own process. The latter have defined own national level of detail (LoD) or information (LoI). BIM cloud allows two approaches: the first approach is characterised by internal databases (bidirectional logic), and the second is the connection of external database by a specific plug-in such as DBLink. The flexibility of MMIS has ensured the various disciplines (not included in the model management process) to define the own level of development, detail and information.

\subsection{The definition of Grade of Accuracy (GoA)}

In recent years, various 3D data capture were applied to BIM projects with different success. Significant studies have been focusing on the generative process of the as-built digital model using the 'Scan to BIM' method. The main benefit is a higher quality of BIM able to improve design process, structural simulation, decay analysis and monitoring results.

Most published studies recognise accuracy as the main quality factor of a point cloud. In engineering, science and statistics fields, the accuracy of a quantified and measured system is the grade of the closeness of measurements of a specific quantity to that quantity's true value. The error resulting from the deviation between and the measured value (3D objects) and the verified value (Pointclouds) is called accuracy. Commonly this factor is expressed as:

$$
\begin{array}{ll}
\text { where } & \mathrm{E}_{\text {acc }}=\mathrm{V}_{\text {mes }}-\mathrm{V}_{\text {ver }} \\
& \mathrm{E}_{\text {acc }}=\text { Accuracy error } \\
& \mathrm{V}_{\text {mes }}=\text { Measured value } \\
& \mathrm{V}_{\text {ver }}=\text { Verified value }
\end{array}
$$

High level of data quality has been addressed in various ways for each case study, by using laser scanning, photogrammetric techniques, geodetic networks, etc. This integration has allowed the definition of quality parameters for each point clouds.

When we were certain that the point clouds parameters (density, size, distance, colours) meet the project requirements, then it became the new GoG 10 of three-dimensional models as described in paragraph 3.1 .

This paper shows a novel method able to define a more accurate evaluation of the quality of each $3 \mathrm{D}$ objects for the generative process of digital models using a 'Scan to BIM' method.

Using test HBIMs of Visconti Bridge and Basilica of Sant' Ambrose a statistical method has been applied to determine the grade of accuracy (GoA) for assuring correct identification of each GoG.

To illustrate the robustness of the proposed method and estimating its descriptive parameters, the results have analysed different deviation value tests obtained by the Automatic Verification System (AVS) able to analyse the following statistics:

- Point counts: instrument designed to measure, memorise and display a large number of points in a point cloud. The value represents the set of points that the device has measured.

- Mean distance: arithmetic measurement of the greatest and least distances between points and 3D objects

- Median distance: sum of a list of values divided by the number of numbers in the list

- Standard deviation: measure that is used to quantify the amount of variation of a set of data values

The GoA represents an effective control system to show the deviation between 3D survey and BIM, defining the maximum GoA of about $1 \mathrm{~mm}$ between point cloud and 3D object.
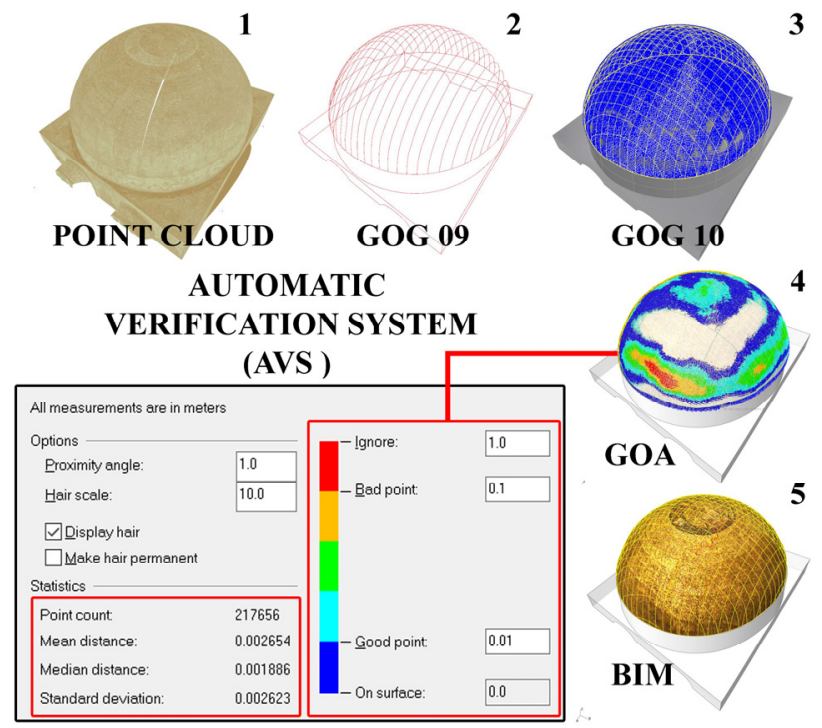

Fig. 6. The Automatic Verification System (AVS ) for 'Scan to BIM'. Ciel d'Oro' Vault, Basilica of Saint Ambrose, Milano. (1) Point Cloud, (2) GoG9 - NURBS from 3D Wireframe, (3) GoG10 - NURBS from a point cloud, (4) GoA - Median Distance is $0,001886 \mathrm{~m}$, Mean Distance 0,002654, Standard Deviaton is $0,002623 \mathrm{~m}$, Point Count 217556, (5) BIM of vaulted system. 


\section{RESULTS}

HBIM of Basilica of Collemaggio required the definition of LoDs oriented to the restoration plan. The main information associated with the model was related to the conservation status of each elements or parts of the building, allowing the update of planned activities or simply supplementing the document with the results of new inspections. The digital model has required other type of GoG during its rehabilitation process.

Structural analysis, finite element analysis and conservation plan have needed the integration of GoG 09 and GoG 10 in order to implement the analysis of vaults and irregular walls.

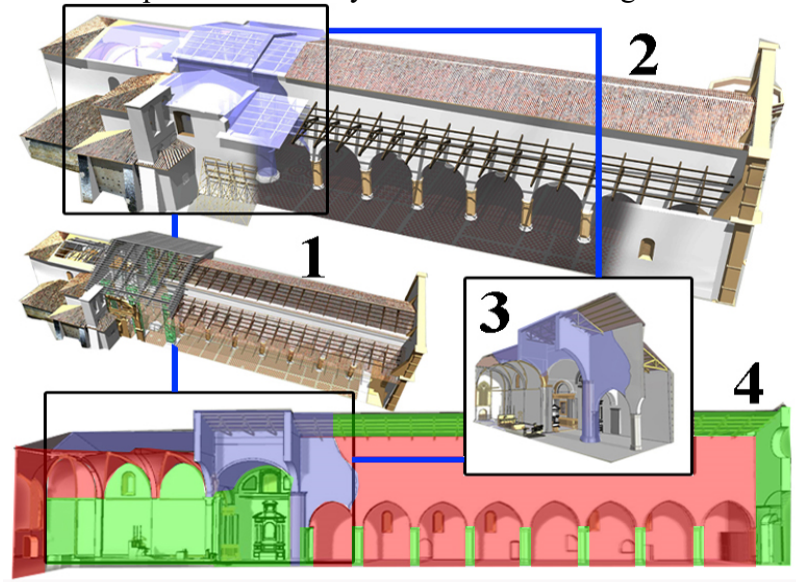

Fig. 7. Basilica of Collemaggio: Revti model (1), BIM for structural analysis (2), Design BIM (3) and HBIM: in red the elements where GoG 10 has been used, in green GoG09 and in blue the other types of GoGs. (4)

The first innovative aspect of HBIM of Masegra Castle has been the development of a virtual environment capable of mixing Augmented Reality (AR) with Virtual Reality (VR) and manage GoG and GoI from multiple data sources. This method has favoured the dissemination and the visualisation of the digital model through different latest generation devices. The second benefit and most articulated has been the creation of intelligent tridimensional elements capable of representing complex elements such as irregular vaults (GoG 10) and arches and roof (GoG 09) in BIM-based applications for structural and finite elements (FEAs) analysis. The GoG 10 has been the main grade to be used for the walls.

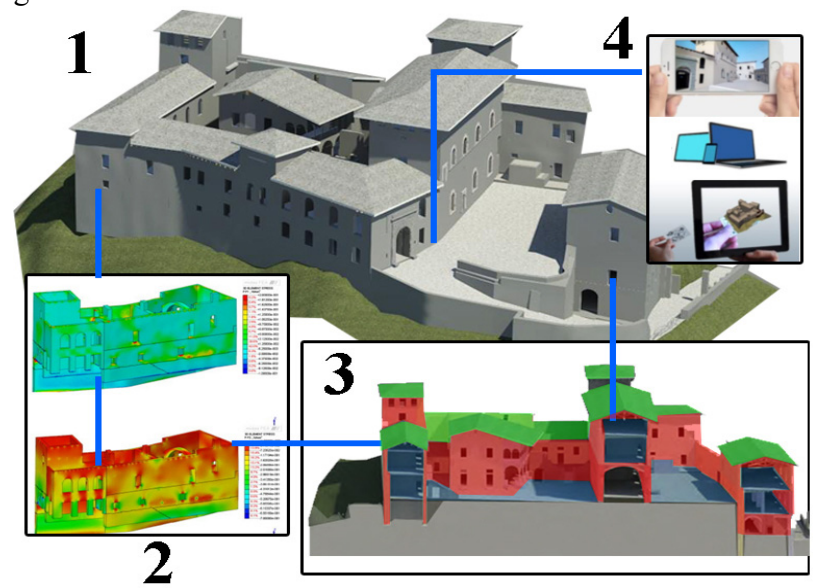

Fig. 8 Masegra Castle Revit model (1), BIM for structural analysis (2), BIM for VR/AR (4). HBIM: in red the elements where GoG 10 has been used, in green GoG09 and in blue the other types of GoGs (3).
The combination of 3D digital survey, AMT, NURBS modeling, parametric application and monitoring datasets required a specific development of a system for archiving and visualising structural health monitoring (SHM) in HBIM of Azzone Visconti bridge.

The availability of a BIM database in a digital cloud have allowed the integration a different kind of data such as reports, tables, graphs, etc. with a representation directly connected to the structure with new GoG 09, and 10 for structural elements such as arches and vaults.

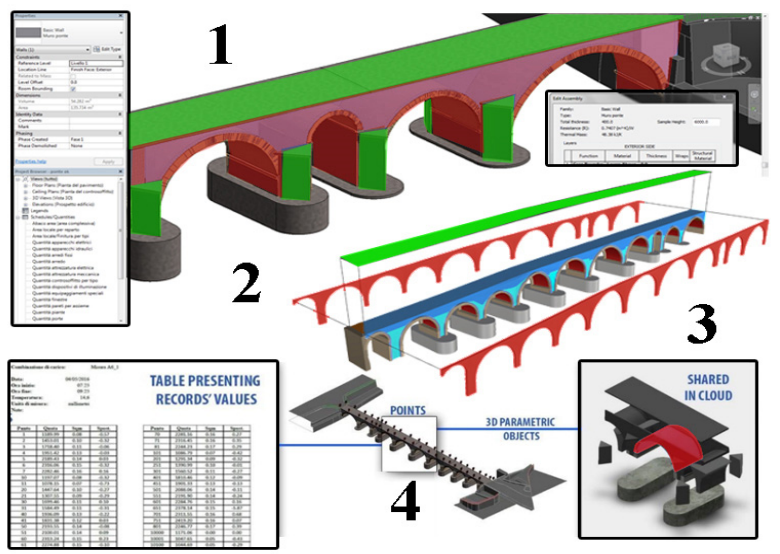

Fig. 9 Visconti bridge: Revti model (1), BIM for structural analysis (2), BIM for VR/AR (3) and BIM for Monitoring (4). In red the elements where GoG 10 has been used, in green GoG09 and in blue the other types of GoGs.

And last but not least, the BIM model of the Basilica of S. Ambrose in Milan was a major challenge for the development of a model capable of interacting with different historical phases. The interpretative analysis of structural elements and their historical archives has allowed generating a model capable of representing complex forms and spreading specific information through different time phases. The third dimension has given way to an innovative methodology that can represent the historical thresholds by finalising the Automatic Verification System (AVS) of the previously mentioned HBIMs.

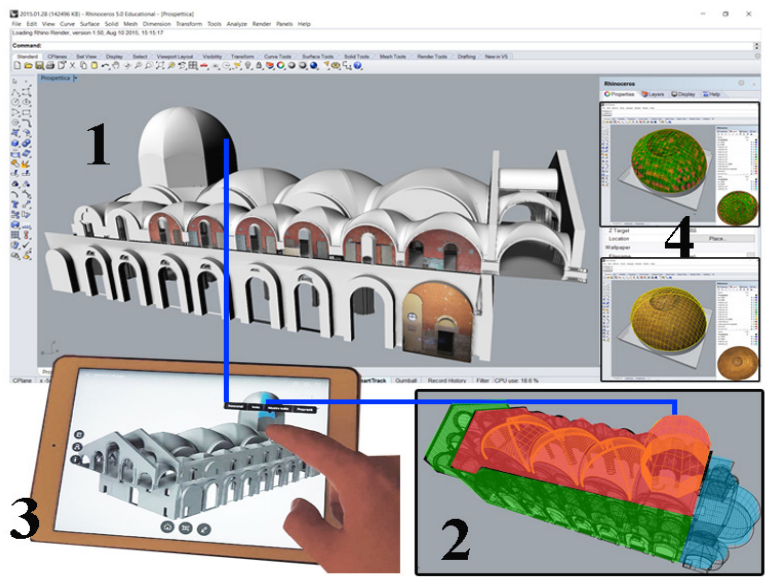

Fig. 10 Basilica of Sant'Ambrose As-built BIM (1), BIM for VR/AR Reality (3), GoA test BIM (4). HBIM: in red the elements where GoG 10 has been used, in green GoG09 and in blue the other types of GoGs (2). 
The definition of a proper GoA has been based on the deviation value between point cloud and $3 \mathrm{D}$ object for each vaulted system of the Basilica. The GoA obtained has identified the reference quality for future generative processes.

To have the proof of the grade of accuracy of the as-built model has represented a solution for determining the quality requirements of 'Scan to BIM' digital models. Lastly, this kind of AVS does not fall under the categories of aid which may be considered in LoD guidelines, but a novel procedure which could be integrated into future research.

\section{CONCLUSION}

The experience gained over the last few years has critically highlighted the need to improve the generative process of asbuilt BIM and their information management.

Modeling Management Information System (MMIS) has allowed outlining a generative process based on Advanced Modeling Techniques (AMT) for different types of analysis, imporoving the information flow during the life cycle of building.

The orientation and integration of AMT, NURBS Modeling and parametric modeling enabled the generation of complex as-built BIMs able to correctly follow the point clouds.

MMIS has led to the definition of grades of generation, information and accuracy, defining how BIM models can be oriented for various project requirements and defined both qualitatively and quantitatively.

The definition of GoGs, GoIs and GoAs is not intended to replace the various national reference regulations but has had the primary purpose to describe how the bidirectional information flow between 3D object and data should be enabled to increase in time.

Industry, scientific research and government institutions can be beneficial from BIM through a process of free bonding.

Future as-built projects will be able to relate to MMTS favouring a precise description of how the model has been generated (GoG), of the linked information $(\mathrm{GoI})$ and which is the grade of accuracy between each 3D Object and the point clouds (GoA). Results show that the defined GoA and the Automatic Verification System (AVS) can be considered as a quality control criteria for 'Scan to BIM'.

Our generations have seen how in a moment they have gone from drawing to china and from 2D CAD drawings to BIM.

For this reason, future research will not stop to represent the buildings by BIM projects, but will certainly find new innovative ways in order to implement new management techniques for our built heritage.

\section{ACKNOWLEDGEMENTS}

The work has also supported by $\mathrm{ABC}$ Department of Politecnico di Milano, Interreg project "La Conservazione Programmata nello Spazio Comune Retico"'(CPRE), the project "Ripartire da Collemaggio" financed by Eni (www.ungiornocollemaggio.com) and the project Ponte Azzone Visconti - Lecco, Indagini, rilievi e verifiche strutturali. The author wants to thank Faculty, ICT, Survey and Monitoring staff of the GIcarus Lab (research centre in ABC Department in Politecnico di Milano), Carleton Immersive Media Studio (CIMS research centre in Carleton University Ottawa Canada) and Autodesk Research Toronto.

\section{REFERENCES}

American Institute of Architects, 2013. AIA Document G2022013: Project Building Information Modeling Protocol Form2.

Banfi F., 2016. Building Information Modelling - A Novel Parametric Modeling Approach Based on 3D Surveys of Historic Architecture. 6th International Conference, EuroMed 2016, Nicosia, Cyprus, October 31 - November 5, 2016, Proceedings, Part II. Digital Heritage. Progress in Cultural Heritage: Documentation, Preservation, and Protection, ISBN 978-3-319-48495-2, pp. 116-127

Banfi F., Barazzetti L., Previtali M., Roncoroni F. (2017). Historic Bim: a new repository for structural health monitoring. The International Archives of the Photogrammetry, Remote Sensing and Spatial Information Sciences, Volume XLII-5/W1, 2017, 22-24 May 2017, Florence, Italy, 6 pages.

Barazzetti L., Brumana R., Oreni D., Previtali M., Roncoroni M. (2014). True-orthophoto generation from UAV images: implementation of a combined photogrammetric and computer vision approach. ISPRS Annals of the Photogrammetry, Remote Sensing and Spatial Information Sciences, Volume II-5, ISPRS Technical Commission V Symposium, 23 - 25 June 2014, Riva del Garda, Italy.

Barazzetti L., Banfi F., Brumana R., Gusmeroli G., Previtali M., Schiantarelli G., 2015. Cloud-to-BIM-to-FEM: Structural simulation with accurate historic BIM from laser scans. Simulation Modelling Practice and Theory, V.57, pp. 71-87.

BIMForum 2013. The level of Development Specification: For Building Information Models, Version: 2013.

CanBIM AEC (CAN) Designers Committee, 2012. AEC (CAN) BIM Protocol: Implementing Canadian BIM Standards for the Architectural, Engineering and Construction industry based on international collaboration, Version 1.0.

Fai, S., Rafeiro, J., 2014. Establishing an appropriate level of detail (LoD) for a building information model (BIM) - West Block, Parliament Hill, Ottawa, Canada. ISPRS

Annals of the Photogrammetry, Remote Sensing and Spatial Information Sciences, 2(5), pp.123-130

Lamine Mahdjoubi, Cletus Moobela, Richard Laing. Providing real-estate services through the integration of 3D laser scanning and building information modelling. Computers in Industry 64, 1272-1281 Elsevier BV, 2013.

NBS. 2016. National BIM Report. https://www.thenbs.com

Piegl, L. A., Tiller, W., 1997. The NURBS book. Springer

Quintero M.S. 2003. The use of three-dimensional techniques of documentation and dissemination in studying Built Heritage Katholieke Universiteit Leuven

Volk R., Stengel J., Schumann F., 2014. Building Information Modeling (BIM) for existing buildings - Literature review and future needs. Automation in Construction, pp. 109-127 